\title{
Evaluating energy and flexibility performance of building clusters
}

\author{
Ilaria Vigna ${ }^{1,2}$, Ina De Jaeger ${ }^{3,4,5}$, Dirk Saelens ${ }^{3,4}$, Marco Lovati ${ }^{1,6}$, Roberto Lollini ${ }^{1}$, Roberta \\ Pernetti ${ }^{1}$ \\ ${ }^{1}$ Eurac Research, Bolzano, Italy \\ ${ }^{2}$ Politecnico di Milano, Milano, Italy \\ ${ }^{3}$ EnergyVille, Genk, Belgium \\ ${ }^{4}$ KU Leuven, Heverlee, Belgium \\ ${ }^{5}$ Flemish Institute for Technological Research (VITO), Mol, Belgium \\ ${ }^{6}$ Università degli studi di Trento, Trento, Italy
}

\begin{abstract}
This work proposes a cluster modelling approach in Modelica language and a methodology to evaluate the energy and flexibility performance of building clusters during the heating period.

Energy flexibility is defined as the building capability to shift energy according to an external forcing factor that, in this study, is the production of a PV plant. Accordingly, a Flexibility Index (FI) is designed to quantify the reduction of the energy demand not covered by renewables comparing reference and smart operation.

The focus on cluster domain enables to exploit the synergies among buildings, renewables and energy infrastructure, while keeping the envelope and HVAC system technological details.

First, a cluster-tailored modelling strategy is presented; then, the methodology to calculate energy flexibility is described and applied to different scenarios, performing a variation of the building thermal mass.
\end{abstract}

\section{Introduction}

The increased penetration of decentralized and fluctuating renewable energy sources in energy distribution networks challenges the stability of both electric and thermal grids.

As part of the solution, (i) energy flexibility will allow for demand and generation management according to local climate conditions, user needs and grid requirements (Reynders at al., 2018) and (ii) the energy management at cluster scale will be an effective way to enable opportunities for the matching improvement between local energy production and consumption.

The concept of energy flexibility, introduced in the framework of the IEA EBC Annex 67 project (IEA EBC Annex 67), is defined as "the capability of a building to react to one or more varying forcing factors, in order to minimize $\mathrm{CO}_{2}$ emissions and maximize the use of renewable energy sources" (Vigna et al., 2018). The forcing factors represent a set of significant boundary conditions that could change during the lifetime of a building and have different levels of frequency.

The flexibility performance is assessed as the amount of energy a building can shift according to external forcing factors. In this study, the production of a PV plant is set as forcing factor and the flexibility performance is therefore quantified as the reduction of the energy demand not covered by renewables, i.e. the improvement of energy usage during periods of available renewable production.

Buildings can provide different flexibility services to reduce peak loads and shift demand in accordance with local RES production, e.g. utilization of thermal mass (Reynders et al., 2013; Le Dréau and Heiselberg, 2016; Foteinaki et al., 2018; Wieß et al., 2018), storage in batteries, charging of electric vehicles and adjustability of the HVAC system use (Jensen et al., 2017).

The novelty of this work lies in the implementation of the energy flexibility quantification methodology defined in Annex 67 project (Grønborg Junker et al., 2018) and in the application to the building cluster scale.

The necessity to shift the focus from single building toward cluster domain is put forward by the European Commission in the "Clean Energy for all Europeans" legislative proposals (EC, 2016a), emphasizing the role of Local Energy Communities (LEC) (EC, 2016b). These LECs are conceived as new market players that are able to generate, consume, store and sell renewable energy. Some prominent clusters in the European context - the BedZED eco-community in London, the Vauban sustainable neighbourhood in Freiburg and Hammarby in Stockholm (Williams, 2016) - demonstrate that the management of a shared distribution network powered by renewables can lead to greater benefits in terms of efficiency, storage and load complementarity due to building usage differences (Metz, 2007).

Therefore, the cluster represents an intermediate level between single building and the whole city and offers the possibility to describe the synergy between buildings and energy grid (unlike the single building) while keeping track of the detailed technological building related aspects (unlike the city scale).

From an energy system perspective, the building cluster is defined as "a group of buildings interconnected to the same energy infrastructure, such that the energy behaviour of each building affects the energy performance of the whole cluster" (Vigna et al., 2018a). This definition does not assign fixed dimensions or boundaries to the building cluster scale, but is based on buildings interconnection that could be physical and/or market related. The physical connection to the same grid allows the exchange of energy between buildings or from a central source towards the buildings. The market aggregation (Eurelectric, 2014) enables the management of the building cluster by a common agent or company 
who can potentially exploit the energy flexibility of the entire cluster (Langham et al., 2013). In the present work, we refer to the physical connection of the buildings forming the cluster.

The complex nature of the building cluster imposes the need for multi-domains modelling tools. According to the review of Allegrini (Allegrini et al., 2015) and the outcomes of the IEA EBC Annex 60 project (IEA EBC Annex 60), Modelica has been identified as one of the proper multi-disciplinary modelling language to address the district level energy system. Modelica libraries are developed using equation-based (acausal) languages instead of imperative languages and enables the implementation of components to support new use cases. In the first part of the Methods section, a cluster-tailored modelling strategy, capable to integrate both building technological characteristics (for both envelope and HVAC system) and energy infrastructure features, is presented. Then, considering as forcing factor the renewable production from a PV system, a methodology to quantify the energy flexibility performance of the cluster is described and applied to two different cluster configurations.

\section{Methods}

To simulate the interaction between buildings and energy grid, a simplified thermodynamic model of the cluster, shown in Figure 1, is defined using Modelica language in Dymola environment (Dassault Systèmes).

Modelica is identified as the proper holistic modelling language for the cluster scale since: (i) several libraries have been developed to enable the sharing/exchange of energy between interconnected buildings and thermal and electrical networks within a single model and (ii) it is possible to model a building cluster considering the proper detail related to both the two scales of project, from technological component and building envelope for single building to district plants and layouts at cluster scale (Allegrini et al., 2015).

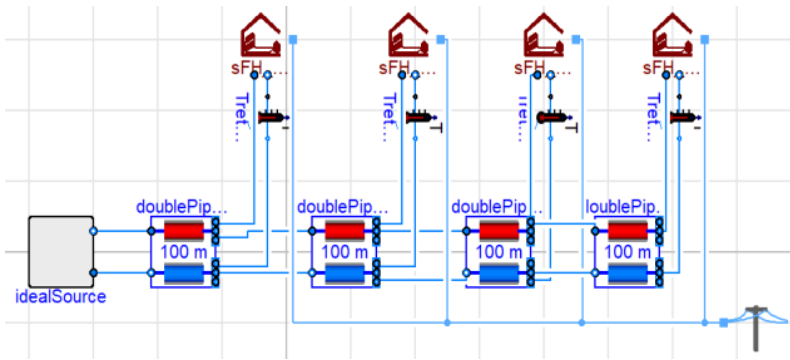

Figure 1: Model of the building cluster integrated with thermal and electric grid in Dymola environment.

Based on the archetypes of Italian building stock presented in the TABULA database (webtool.buildingtypology.eu), the geometrical and thermal properties of the selected buildings are translated into reduced-order Modelica models using the Python package TEASER developed by RWTH Aachen (Remmen et al., 2017).

The simulation of different cluster configurations is performed to obtain different energy demand profiles at cluster scale and then evaluate the cluster energy and flexibility performance.

\section{Building cluster configurations}

The buildings adopted for this study are referred to the archetypes presented in the IEE-Project TABULA database for the Italian building stock typology of the detached Single Family House (SFH) (Corrado et al., 2011) of the construction period after 2006. Such construction period is selected with the aim to investigate the flexibility performance of new buildings with local integrated renewable energy sources.

The geometrical properties of the building typology used in simulations are summarised in Table 1.

As assumption, the internal walls and floor have the same surface area as respectively the outer walls and the ground floor. The thermal transmittance values of the building envelope components are set accordingly to Italian requirements for new buildings defined in D.M. 26.06.2015 (Decreto del Ministero dello Sviluppo Economico, 2015): $U$-value of $0.22 \mathrm{~W} / \mathrm{m}^{2} \mathrm{~K}$ for the opaque elements (exterior walls, ground slab, roof) and $U$-value of $1.1 \mathrm{~W} / \mathrm{m}^{2} \mathrm{~K}$ for the transparent elements.

As first application of the methodology, two different cluster configurations are simulated, performing a variation of the building components' thermal mass. For the exterior walls, roof, internal walls and internal floor, two different levels of thermal mass -heavy $(\mathrm{H})$ and light (L)-, respectively referred to two different structural cores (concrete and laminated timber) are considered. The main thermal properties are reported in Table 2.

Table 1: Geometrical properties of the building typology used in simulations.

\begin{tabular}{|l|l|}
\hline \multicolumn{2}{|l|}{ Single Family House SFH } \\
\hline Volume & $607 \mathrm{~m}^{3}$ \\
\hline Gross heated area & $174 \mathrm{~m}^{2}$ \\
\hline Number of floors & 2 \\
\hline Component area \\
\hline Exterior walls & $225.3 \mathrm{~m}^{2}$ \\
\hline Ground slab & $96.4 \mathrm{~m}^{2}$ \\
\hline Roof & $96.4 \mathrm{~m}^{2}$ \\
\hline Window area & $21.7 \mathrm{~m}^{2}$ \\
\hline Internal walls & $225.3 \mathrm{~m}^{2}$ \\
\hline Internal floor & $96.4 \mathrm{~m}^{2}$ \\
\hline
\end{tabular}

Table 2: Thermal properties of building components for different cluster configurations.

\begin{tabular}{|l|c|c|}
\cline { 2 - 3 } \multicolumn{1}{c|}{} & $\begin{array}{c}\text { Heavy } \\
\text { configuration }(\mathbf{H})\end{array}$ & $\begin{array}{c}\text { Light } \\
\text { configuration }(\mathbf{L})\end{array}$ \\
\hline Structural core & Concrete & Laminated timber \\
\hline U-value $\left[\mathrm{W} / \mathrm{m}^{2} \mathrm{~K}\right]$ & 0.22 & 0.22 \\
\hline Heat capacity $[\mathrm{MJ} / \mathrm{K}]$ & 68 & 25 \\
\hline $\begin{array}{l}\text { Periodic thermal } \\
\text { transmittance } \mathrm{Y}_{\text {ie }}\left[\mathrm{W} / \mathrm{m}^{2} \mathrm{~K}\right]\end{array}$ & 0.014 & 0.068 \\
\hline
\end{tabular}

In each configuration, the cluster is composed of four residential single family detached houses with four different stochastic occupant behaviour, connected to a district heating system that allows thermal energy exchange between buildings. 


\section{Building cluster models}

The building cluster models are set out following a series of methodological steps reported in the following subsections.

Translation of geometrical and thermal properties of buildings in Modelica language

To generate the reduced-order models, the open-source Python package TEASER (Remmen et al., 2017) is employed, although in a slightly adapted version. The original version of TEASER imports a CityGML model, containing the building geometry, construction year, the number of floors and their height as well as the building height, enriches these data with material layers for all building elements based on the German TABULA project and exports Aixlib or IBPSA Modelica models. For this work, as no CityGML model of the buildings was available, an additional import feature is implemented in TEASER, more in particular import from a csv-file. The csv-file contains the same data as required for the CityGML file, but considers only 8 possible orientations for the building elements (N, NE, E, SE, S, SW, W and NW) (De Jaeger et al., 2018) and only one tilt for all the pitched roof parts of a particular building. Additionally, the German data, used for the data enrichment, are replaced by Italian data. Finally, the export of IBPSA reduced-order models to the IDEAS Modelica library (Jorissen et al., 2018) is implemented.

Definition of the building cluster numerical model in Dymola environment

The IBPSA reduced-order model for the thermal zone is included in the IDEAS building model. The cluster is modelled in IDEAS library and simulations are performed in Dymola environment. The IDEAS-Integrated District Energy Assessment Simulations (Open $\underline{\text { IDEAS) }}$ ) library allows simultaneous transient simulation of thermal and electrical systems at both building and feeder level. The main items included in the model are described below.

\section{- Boundary conditions}

The weather data conditions are referred to the city of Bolzano, Italy. A Typical Metereological Year (TMY) file is obtained from the Meteonorm database (Meteonorm).

\section{- Building envelope}

To reduce computational effort and keep an adequate level of accuracy, the building envelope is described through a Reduced-Order Model (ROM), shown in Figure 2. The distributed thermal mass of building envelope components is defined as a model of resistancecapacitance (RC) network analogue to electric circuits, as described in Lauster et al. (2015). The thermal masses of each building envelope component (external walls, ground slab, roof and internal walls) are represented as a vector of capacitances. Solar gains, internal gains and heating are distributed over the capacities (Pernetti et al., 2013; Pernetti et al., 2014). Additionally, for each envelope component a vector of resistances is defined, representing the radiative heat transfer between building components and the convective heat transfer between building components and both the outdoor and the inner air of the zone. All the values of the resistances and capacitances are automatically calculated within TEASER, before generating the IDEAS building models.

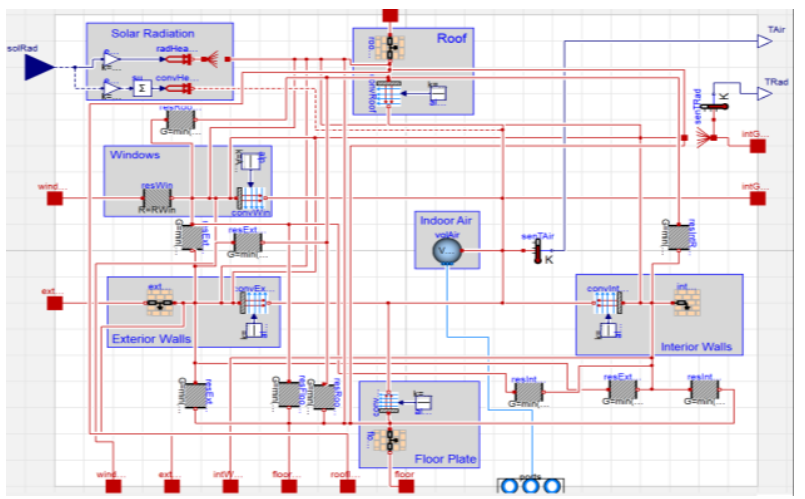

Figure 2: Reduced-order model of the structure of each building forming a cluster, using resistors and capacitors components of the library IDEAS.

\section{- $\underline{\text { Systems }}$}

The buildings are equipped with radiators as heat emission system, connected to the district heating network through a heat exchanger. As the focus of this work is on the heating period, no cooling system is included. The domestic hot water circuit is modelled as a hot water storage system. The mechanical ventilation system is set with a constant ventilation rate of $0.51 / \mathrm{h}$, with recuperation efficiency of $84 \%$.

\section{- Occupancy and appliances}

The residential occupancy and appliances use profiles are stochastically defined using the Load Profile Generator tool (Load Profile Generator). Four different load profiles are created:

- Profile \#1: Family consisting of 2 adults (both workers) and 3 children;

- $\quad$ Profile \#2: Couple of adults (1 worker);

- Profile \#3: Family consisting of 1 adult woman (worker) and 2 children;

- $\quad$ Profile \#4: Single adult man (worker).

The stochastic data referred to heat flows from occupants and appliances are imported in the model as a matrix. The temperature set-points are not influenced by the stochastic occupant behaviour, as they are specifically designed and used as inputs, as described in the Flexibility assessment section.

\section{- District heating}

The district heating network is represented through a succession of distribution double pipe models (van der Heijde et al., 2017), supplied by an ideal source. For the purpose of this analysis, aimed to implement the methodology to evaluate the flexibility of clusters correlating the heating energy demand to the PV production as a forcing factor, we adopt as an ideal source a large-scale heat pump electrically driven. This technological system is in line with the limited size of the cluster and with proven experiences across Europe of large scale heat pumps (EHPA, 2017; H2020 COOL DH project). 
Definition of the renewable energy production profile of the local installed cluster PV system

The photovoltaic design software POW tool is used to define a reference PV system capacity and solar collectors' position for the cluster according to an energy optimization, as described in Vigna et al. (2018b) and Lovati et al. (2018). The resulting renewable energy production profile serves as a forcing factor (i.e. an external signal to which the building cluster was supposed to react) for the energy flexibility assessment of the cluster, as explained below. The monthly values of the production from the PV plant are reported in Figure 3. The PV capacity installed in the cluster is of $14.33 \mathrm{kWp}$. The modules dimensions are $1.989 \times 1.63 \mathrm{~m}$, the static performance ratio coefficient is of 0.8 and the efficiency assumed is of $17 \%$.

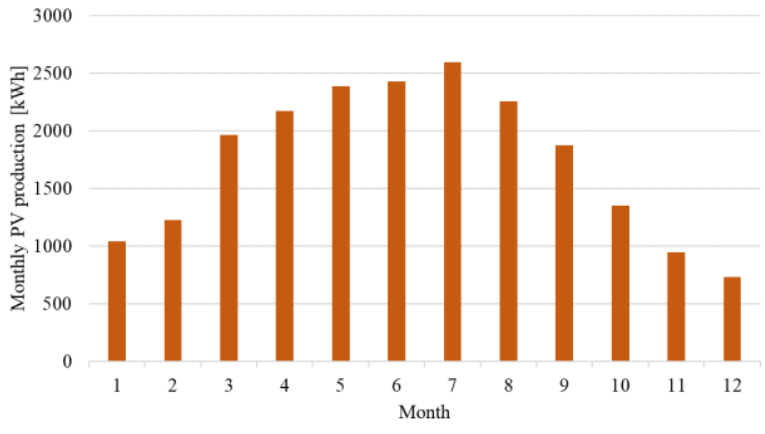

Figure 3: Monthly renewable energy production from the cluster PV plant.

\section{Flexibility assessment}

In line with the energy flexibility characterization methodology set out in Annex 67 project (Grønborg Junker et al., 2018), energy flexibility can be calculated as the measure of the cluster reaction to external forcing factors. In other words, the flexibility is the difference in terms of net energy use, between the cluster managed by a control system that is not aware of the forcing factor (reference operation), and the control sharpened according to the forcing factor (smart operation). In the present work, the availability of local RES production from a PV system is settled as forcing factor.

The modulation of the temperature set-point is used as strategy for affecting the timing operation and the power requested by the heating system. For the heating period (January-April and October-December), two different temperature set-point controllers of the heating system are defined (an example is illustrated in Figure 6a-b and Figure 7a-b):

- for the reference operation $(\mathrm{R})$ of the heavy weight $(\mathrm{H})$ and of the light weight (L) clusters, a set-point of $20^{\circ} \mathrm{C}$ is set during the day $(7 \mathrm{am}-11 \mathrm{pm})$ according to the standard EN15251 (CEN, 2007), while a set-back of $16^{\circ} \mathrm{C}$ is fixed for the night hours (11pm-7am).

- for the smart operation (S) of the heavy weight $(\mathrm{H})$ and of the light weight (L) clusters, a forcing factor-aware controller is designed based on the monthly available RES produced by the PV system. First, a forcing factor signal is defined: for each month of the heating period, the maximum value of the renewable energy produced is sorted; this value is associated to the upper limit of the forcing factor signal of $+2{ }^{\circ} \mathrm{C}$ (time intervals with high renewable production), while the lower limit of the signal of $-2{ }^{\circ} \mathrm{C}$ is referred to time intervals with no renewable production. The limits of comfortable conditions of $20^{\circ} \mathrm{C}$ $\pm 2{ }^{\circ} \mathrm{C}$ are chosen in accordance to Category IIIAcceptable, moderate level of expectation defined in the standard EN15251 (CEN, 2007). Then, in order to define a proper signal for controlling the building set-point temperature according to the PV production, we have subdivided the range between the null and the maximum production in nine intermediate intervals. Each interval indicates a variation of the set-point of $\pm 0.5^{\circ} \mathrm{C}$ respect to the adjacent intervals. During the night hours, no signals are applied and the temperature set-point is kept the same as the reference operation building $\left(16{ }^{\circ} \mathrm{C}\right)$.

In this study, the energy flexibility is defined as the ability of the building to minimize the heating energy usage during the absence of renewable energy sources (RES) production and maximize it during periods of available renewable production. Therefore, the final objective of the energy flexible cluster is to maximize the use of RES and reduce the use of non-renewable energy. The flexibility of each cluster configuration is quantified considering the Flexibility Index FI, expressed as the difference between the residual demand of the reference cluster $\mathrm{q}_{\text {match }}{ }^{\mathrm{REF}}$ and the residual demand of the smart cluster $\mathrm{q}_{\text {match }}$ SMART divided by the reference heating demand $\mathrm{q}_{\text {consumed }}{ }^{\mathrm{REF}}$ as reported in Equation (1). All the terms under the integrals are expressed as power (i.e. in $\mathrm{kW})$.

$$
\mathrm{FI}=\int\left(\mathrm{q}_{\text {match }}^{\mathrm{REF}}-\mathrm{q}_{\text {match }}^{\mathrm{SMART}}\right) d t / \mathrm{Q}_{\text {consumed }}^{\mathrm{REF}}
$$

For the heating period, the residual demand of the clusters $\mathrm{Q}_{\text {match }}{ }^{\mathrm{REF}}$ and $\mathrm{Q}_{\text {match }}{ }^{\mathrm{SMART}}$ are respectively calculated as the maximum value between 0 and the difference between the energy demand of the cluster and the renewable energy produced:

$$
\begin{gathered}
\mathrm{Q}_{\text {match }}^{\text {REF }}=\int \max \left(0, \mathrm{q}_{\text {consumed }}^{\text {REF }}-\mathrm{q}_{\text {produced }}^{\text {REF }}\right) d t \\
\mathrm{Q}_{\text {match }}^{\text {SMART }}=\int \max \left(0, \mathrm{q}_{\text {consumed }}^{\text {SMART }}-\mathrm{q}_{\text {produced }}^{\text {SMART }}\right) d t
\end{gathered}
$$

Thus, the residual demand refers to the energy demand not covered by RES and must therefore be satisfied with non-renewable energy sources.

In the next section, the results obtained from the simulations for the energy and flexibility performance of the clusters are presented and discussed.

\section{Results and Discussion}

\section{Energy performance}

In Figure 4, the monthly heating demand of the heavy $\mathrm{H}$ (top) and light L (bottom) cluster configurations are reported:

- the grey bars show the total heating demand of the cluster during the reference operation (R), i.e. the energy performance of the cluster before considering the contribution of the PV production and without the smart control; 

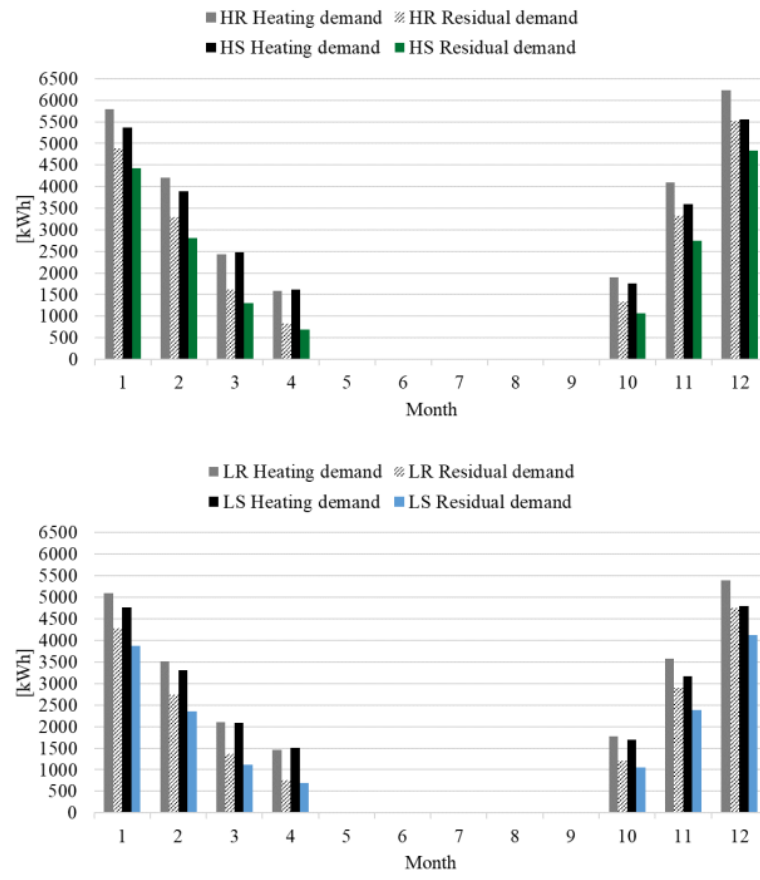

Figure 4: Monthly heating demand of the heavy weight (H) (top) and light weight (L) (bottom) simulated cluster configurations. Reference case $(R)$ versus smart case $(S)$.

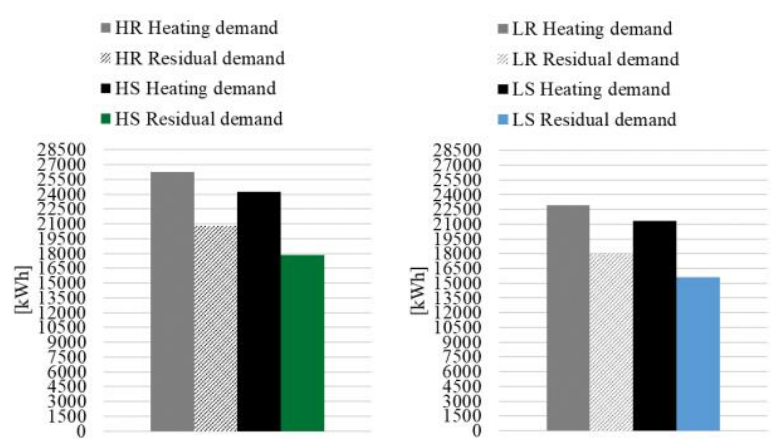

Figure 5: Yearly heating demand of the heavy weight (H) (left) and light weight (L) (right) simulated cluster configurations. Reference case $(R)$ versus smart case $(S)$.

Table 3: Yearly heating demand values for different cluster configurations.

\begin{tabular}{|l|c|c|c|c|}
\cline { 2 - 5 } \multicolumn{1}{c|}{} & \multicolumn{2}{c|}{$\begin{array}{c}\text { Heavy configuration } \\
\text { (H) }\end{array}$} & \multicolumn{2}{c|}{$\begin{array}{c}\text { Light configuration } \\
\text { (L) }\end{array}$} \\
\cline { 2 - 5 } & $\begin{array}{c}\text { Reference } \\
\text { (R) }\end{array}$ & $\begin{array}{c}\text { Smart } \\
(\mathrm{S})\end{array}$ & $\begin{array}{c}\text { Reference } \\
(\mathrm{R})\end{array}$ & $\begin{array}{c}\text { Smart } \\
(\mathrm{S})\end{array}$ \\
\hline $\begin{array}{l}\text { Heating } \\
\text { demand } \\
{[\mathrm{kWh}]}\end{array}$ & 26262 & 24263 & 22900 & 21338 \\
\hline $\begin{array}{l}\text { Residual } \\
\text { demand } \\
{[\mathrm{kWh}]}\end{array}$ & 20804 & 17865 & 18023 & 15600 \\
\hline
\end{tabular}

- the grey dashed bars show the residual demand of the cluster during the reference operation (R), i.e. the energy savings of the cluster considering only the contribution of the PV production (without smart control);
- the black bars show the total heating demand of the cluster during smart operation (S), i.e. the energy performance of the cluster considering only the contribution of the smart control;

- the green bars (for the heavy $\mathrm{H}$ cluster configuration) and the blue bars (for the light L cluster configuration) show the residual demand of the cluster during smart operation (S), i.e. the energy savings of the cluster considering both the contributions of the PV production and the smart control affecting the timing operation of the heat pump.

The values of the residual demand of the simulated configurations $\left(\mathrm{Q}_{\text {match }}{ }^{\mathrm{REF}}\right.$ and $\left.\mathrm{Q}_{\text {match }}{ }^{\mathrm{SMART}}\right)$ are calculated as shown in Equation 2 and Equation 3. For the whole heating period, it is visible that both the PV system and the smart control contributions result in significant energy savings.

Considering the yearly energy demand shown in Figure 5 and Table 3, for both the heavy weight $(\mathrm{H})$ and the light weight (L) configurations the smart operation (S) improved the energy usage during periods of available renewable production, resulting in a reduction of $14 \%$ of the residual demand (i.e. the energy demand not covered by renewables) compared to the reference $(\mathrm{R})$ operation.

The daily trends for two representative days of January and March are respectively presented in Figure 6 and Figure 7. Figure $6 a$ and Figure $7 \mathrm{a}$ report the variation of the smart set-points (red lines) compared to the reference set-points (black dashed).

Figure $6 \mathrm{~b}$ and Figure $7 \mathrm{~b}$ show in grey bars the forcing factor signal based on available renewable energy produced by the PV system.

Figure $6 \mathrm{c}$ and Figure $7 \mathrm{c}$ report the indoor temperature trends for one representative building of the cluster for both heavy $(\mathrm{H})$ and light $(\mathrm{L})$ configurations, during reference $(\mathrm{R})$ and smart $(\mathrm{S})$ operation. It is visible that during the day and with the smart control enabled, the indoor temperature in the heavy weight building is lower than the one in the light weight building. This is because the solar and internal gains are insufficient to effectively charge a high thermal mass. Therefore, when the indoor air temperature is above the set-point and the heating system is off, the indoor air of the heavy weight building cools down more rapidly than the light weight building due to the heat released from the indoor air volume to the walls.

Figure 6d-e and Figure 7d-e present the heating demand of the reference (black dashed line) and smart configuration (green line for the heavy cluster and blue line for the light cluster) and the trend of the PV production (grey dotted line). What the smart control tries to do is to decrease the heating demand during periods of null PV production and shift/increase it during periods of available renewable energy. During the representative days of January, it is not possible to completely shift the smart heating demand curve in correspondence to the PV 

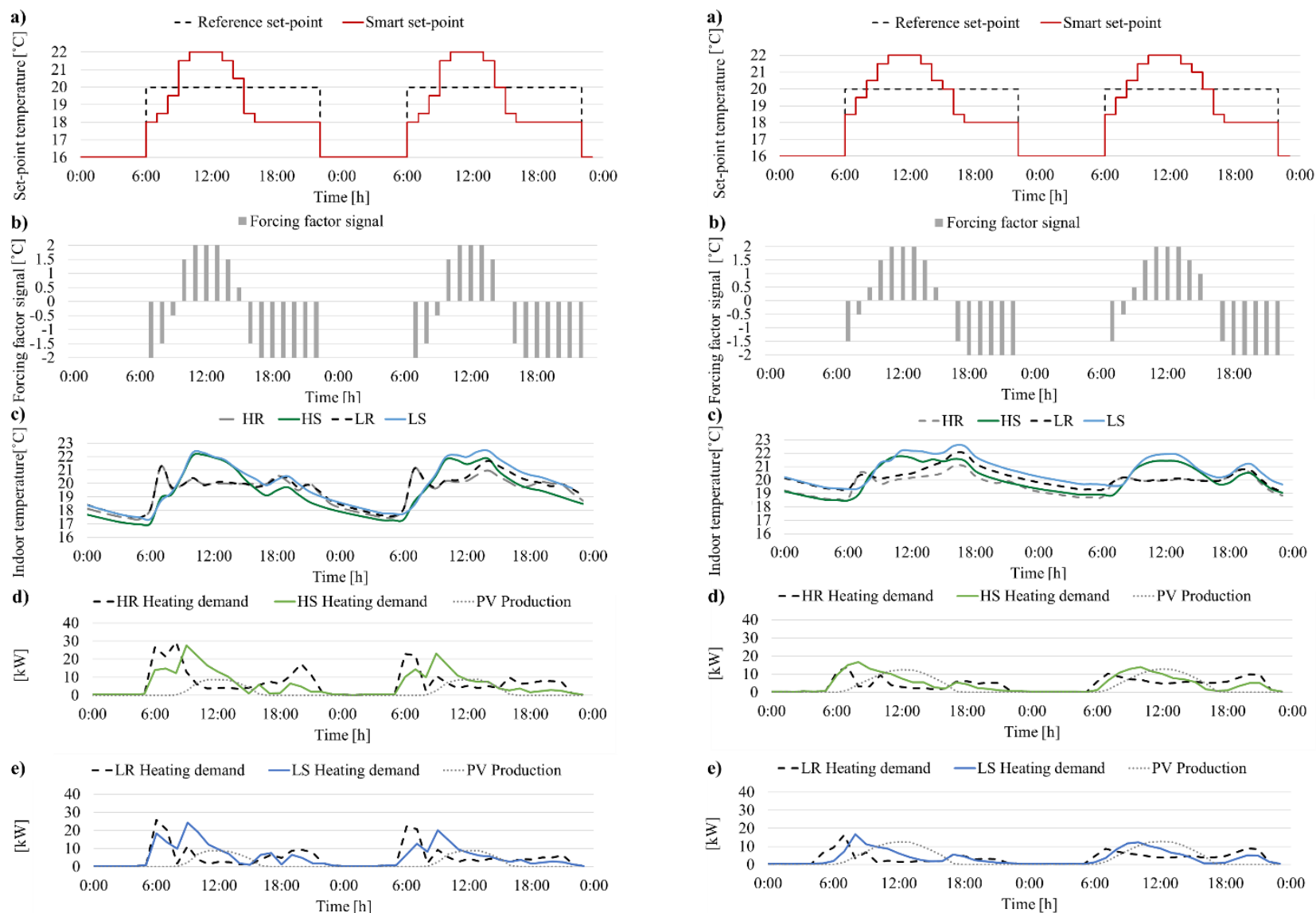

Figure 6: Daily trends for two representative days in January. a) Temperature set-point of reference and smart operation; b) Forcing factor signal; c) Indoor temperature of one representative building of the cluster for both heavy weight $(H)$ and light weight $(L)$ configurations, during reference $(R)$ and smart $(S)$ operation; d) Heating demand of the simulated heavy weight $(H)$ configurations (reference case $(R)$ versus smart case $(S))$ and $P V$ production profile; e) Heating demand of the simulated light weight $(L)$ configurations

(reference case $(R)$ versus smart case $(S)$ and $P V$ production profile.

production curve because the PV starts to produce at around 9am but the heating system has to be turned on at $7 \mathrm{am}$ to ensure comfort conditions, both in reference and smart operation. Anyway, the smart control positively contributes to decrease the energy demand during periods of absence of renewable production and increase it during periods of available renewable production for both the heavy and the light configurations. During the representative days of March, the PV system starts in advance to produce renewable energy (7am) and thus it is visible a better correspondence with the trend of the heating demand. Here again, the smart control lowers the demand during periods without renewable energy production and tries to shift it during periods of available renewable energy for both the heavy and light configurations.
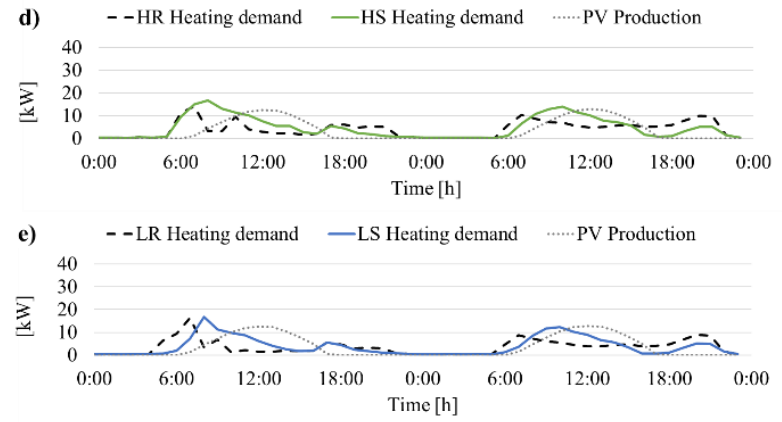

Figure 7: Daily trends for two representative days in March. a) Temperature set-point during reference and smart operation; b) Forcing factor signal; c) Indoor temperature of one representative building of the cluster for both heavy weight $(H)$ and light weight $(L)$ configurations, during reference $(R)$ and smart $(S)$ operation; d) Heating demand of the simulated heavy weight $(H)$ configurations (reference case $(R)$ versus smart case $(S)$ and $P V$ production profile; e) Heating demand of the simulated light weight $(L)$ configurations (reference case $(R)$ versus smart case $(S)$ and $P V$ production profile.

\section{Flexibility performance}

The values of the Flexibility Index FI of the two configurations, calculated using Equation 1, are shown in Figure 8 and Figure 9. From the monthly results, it is visible that in the cold months of January, November and December, the light cluster is more flexible than the heavy cluster. On the contrary, during the warmer months of April and October the FI for the heavy cluster is much higher than for the light cluster; however, the residual demand is quite low in these months, so the energy saving is limited.

As result, on annual basis, the FI value obtained by both cluster is the same (0.11). This means that in this case, the higher thermal mass does not increase the flexibility index of the building. 


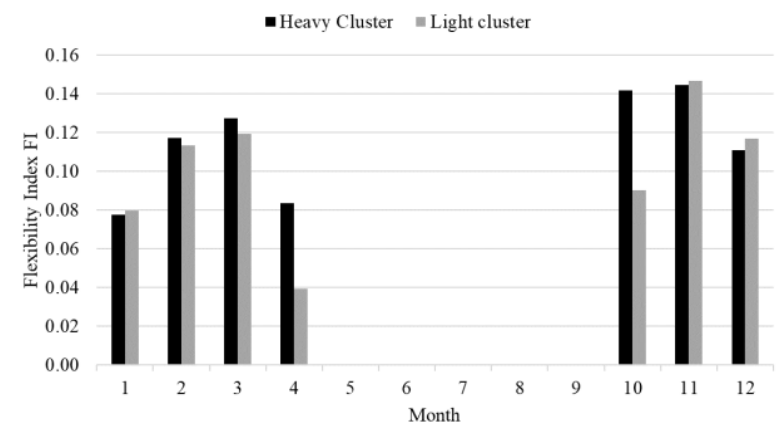

Figure 8: Monthly values of the Flexibility Index FI for the simulated cluster configurations.

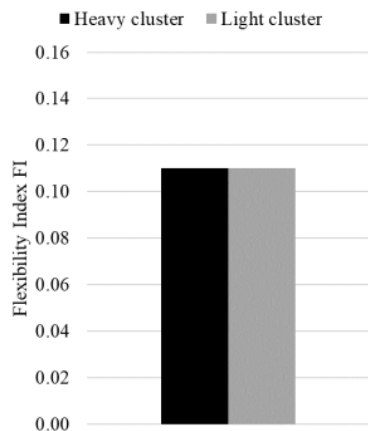

Figure 9: Yearly values of the Flexibility Index FI for the simulated cluster configurations.

\section{Conclusion}

This paper presents a methodology to define building cluster models connected to a thermal network in Modelica language. Two building cluster configurations are modelled using the IDEAS library and the energy and flexibility performance are evaluated for the heating period. The availability of local renewable production from a PV system is settled as forcing factor and the flexibility performance is quantified as the reduction of the heating energy demand not covered by renewables. Based on the methodology defined in IEA EBC Annex67 project, the energy flexibility potential of different scenarios is assessed. A scenario for reference operation of the buildings with constant heating temperature setpoint at $20{ }^{\circ} \mathrm{C}$ during the day $(7 \mathrm{am}-11 \mathrm{pm})$ and $16{ }^{\circ} \mathrm{C}$ during the night $(11 \mathrm{pm}-7 \mathrm{am})$ is initially simulated. According to the availability of local renewable energy, a smart set-point is provided based on a forcing factor signal (temperature modulation of $20{ }^{\circ} \mathrm{C} \pm 2{ }^{\circ} \mathrm{C}$ with variation at intervals of $0.5^{\circ} \mathrm{C}$ ), with the aim of decreasing the heating demand during periods of zero PV production and shift it during periods of available renewable energy.

For the whole heating period, the smart operation of both the heavy and the light smart cluster configurations enables an improvement of RES usage, with a consequent reduction of the residual demand (i.e. non-renewable energy demand) of $14 \%$ compared to the reference residual demand.

For both cluster configurations, the flexibility performance is evaluated by defining a Flexibility Index (FI) to quantify the amount of energy that can be shifted towards RES-availability through the smart control operation in comparison to the reference case. In this first application, the FI obtained for both configurations is the same, so in this case the higher thermal mass of the cluster does not increase the flexibility index.

To conclude, this work introduces a preliminary approach for modelling a building cluster in Modelica language and a methodology to evaluate the cluster flexibility performance. There are some issues that will be finetuned in the next developments of the model, e.g. the ventilation rate defined according to the forcing factor, an improved storage capacity model of the envelope and the analysis of the cooling demand. In addition, the methodology for the flexibility assessment will be applied considering different forcing factors (e.g. energy price or $\mathrm{CO}_{2}$ intensity of the energy used) and further variations in the cluster features (e.g. insulation level, building use, building typology). Moreover, the control strategies will be improved to enhance the flexible behaviour of the whole building cluster and more detailed comfort evaluations will be performed.

\section{Acknowledgement}

This work is part of IEA EBC Annex 67 Energy Flexible Buildings. The activities are carried out in the framework of the project INTEGRIDS: Studio dell'integrazione di reti elettriche e termiche con la flessibilità energetica degli edifici, funded by the European Regional Development Fund PO FESR EFRE 2014-2020 Provincia autonoma di Bolzano-Alto Adige, under contract No1042 and of the project EnergyMatching, funded by the European Union's Horizon 2020 research and innovation programme under grant agreement No768766.

\section{References}

Allegrini, J., Orehounig, K., Mavromatidis, G., Ruesch, F., Dorer, V., Evins, R. (2015). A review of modelling approaches and tools for the simulation of districtscale energy systems. Renewable and Sustainable Energy Reviews 52, 1391-1404.

CEN (2007). Indoor environmental input parameters for design and assessment of energy performance of buildings addressing indoor air quality, thermal environment, lighting and acoustics (EN 15251).

Corrado, V., Ballarini, I., Corgnati, S. P., Talà, N. (2011). Building Typology Brochure - Italy. Fascicolo sulla Tipologia Edilizia Italiana. Politecnico di Torino.

De Jaeger, I, Reynders, G., Ma, Y., Saelens, D. (2018). Impact of building geometry description within district energy simulations. Energy 158, 1060-1069.

Decreto del Ministero dello Sviluppo Economico (2015). Applicazione delle metodologie di calcolo delle prestazioni energetiche e definizione delle prescrizioni e dei requisiti minimi degli edifici (D.M. 26.06.2015).

Dessault Systèmes https://www.3ds.com/

EC (2016a). Clean energy for all europeans. COM(2016) 860 final. Brussels, 30.11.2016.

EC (2016b). Proposal for a Directive of the European Parliament and of the Council on common rules for 
the Internal Market in Electricity (Recast). $\operatorname{COM}(2016) 864$ final.

EHPA (2017). Large scale heat pumps in Europe. ICHP Working Group, Belgium, 2017. https://www.ehpa.org/fileadmin/red/03._Media/03.02 Studies and reports/Large heat pumps in Europe MDN_II_final4_small.pdf

Eurelectric (2014). Flexibility and Aggregation Requirements for their interaction in the market. Eurelectric paper. Brussels (Belgium).

Foteinaki, K., Rongling, L., Heller, A., Rode, C. (2018). Heating system energy flexibility of low-energy residential buildings. Energy and Buildings 180, 95-108.

Grønborg Junker, R., Ghasem Azar, A., Amaral Lopes, R., Byskov Lindberg, K., Reynders, G., Relan, R., Madsen, H. (2018). Characterizing the energy flexibility of buildings and districts. Applied Energy 225, 175-182.

H2020 COOL DH project http://www.cooldh.eu/demosites-and-innovations-in-cool-dh/osterby-hojetaastrup/

IEA EBC Annex 60 http://www.iea-annex60.org/

IEA EBC Annex 67 http://www.annex67.org/

International Organisation for Standardisation (2008). Energy performance of buildings -- Calculation of energy use for space heating and cooling (ISO 13790).

Jensen, S.Ø., Marszal-Pomianowska, A., Lollini, R., Pasut, W., Knotzer, A., Engelmann, P., Stafford, A., Reynders, G. (2017). IEA EBC Annex 67 Energy Flexible Buildings. Energy and Buildings 155, 24-34.

Jorissen, F., Reynders, G., Baetens, R., Picard, D. Saelens, D., Helsen, L. (2018). Implementation and Verification of the IDEAS Building Energy Simulation Library. Journal of Building Performance Simulation 11 (6), 669-688.

Le Dréau, J., Heiselberg, P. (2016). Energy flexibility of residential buildings using short term heat storage in the thermal mass. Energy 111, 991-1002.

Langham, E., Cooper, C., Ison, N. (2013). Virtual net metering in Australia: Opportunities and barries. UTS. Sydney (Australia).

Lauster, M., Teichmann, J., Fuchs, M., Streblow, R., \& Müller, D. (2014). Low order thermal network models for dynamic simulations of buildings on city district scale. Building and Environment 73, 223-231.

Load Profile Generator https://www.loadprofilegenerator.de/

Lovati, M., Salvalai, G., Fratus, G., Maturi, L., Albatici, R., Moser, D. (2018). New method for the early design of BIPV with electric storage: a case study in northern Italy. Sustainable Cities and Society, (in press).

Meteonorm www.meteonorm.com

Metz, B., Davidson, O.R., Bosch, P.R., Dave, R., Meyer, L.A. (edited by). (2007). Mitigation of climate change: Contribution of working group III to the fourth assessment report of the Intergovernmental Panel on Climate Change. Cambridge University Press.

OpenIDEAS https://github.com/open-ideas/IDEAS

Pernetti, R., Prada, A., Baggio, P. (2013). On the influence of several parameters in energy model calibration: The case of a historical building. Building Simulation Applications, 263-272.

Pernetti, R., Prada, A., Baggio, P.(2014). The calibration process of building energy models. Green Energy and Technology, 215-252.

Remmen, P., Lauster, M., Mans, M., Fuchs, M., Osterhage, T., Müller, D. (2018). TEASER: an open tool for urban energy modelling of building stocks. Journal of Building Performance Simulation 11(1), 84-98.

Reynders, G., Nuytten, T., Saelens, D. (2013). Potential of structural thermal mass for demand-side management in dwellings. Building and Environment 64, 187-199.

Reynders, G., Diriken, J., Saelens, D. (2017). Generic characterization method for energy flexibility: Applied to structural thermal storage in residential buildings. Applied Energy 198, 192-202.

Reynders, G., Amaral Lopes, R., Marszal-Pomianowska, A., Aelenei, D., Martins, J., Saelens, D. (2018). Energy flexible buildings: an evaluation of definitions and quantification methodologies applied to thermal storage. Energy and Buildings 166, 372-390.

Van der Heijde, B., Aertgeerts, A., Helsen, L. (2017). Modelling steady-state thermal behaviour of double thermal network pipes. International Journal of Thermal Sciences 117, 316-327.

Vigna, I. Pernetti, R., Pasut, W., Lollini, R. (2018a). New domain for promoting energy efficiency: Energy Flexible Building Cluster. Sustainable Cities and Society 38, 526-533.

Vigna, I. Pernetti, R., Lovati, M. (2018b). A modelling approach for maximizing energy matching at building cluster and district scale. Proceedings of BSO Cambridge, Cambridge (UK), 11-12 September 2018.

Voss, K., Sartori, I., Napolitano, A., Geier, S., Gonzalves, H., Hall, M., Heiselberg, P., Weiden, J., Candanedo, J.A., Musall, E., Karlsson, B., Torcellini, P. (2010). Load matching and grid interaction of net zero energy buildings. Proceedings from $8^{\text {th }}$ EuroSun conference. Graz (Austria), 28 September-1 October 2010.

Weiß, T., Fulterer, A.M., Knotzer, A. (2018). Energy flexibility of domestic thermal loads - a building typology approach of the residential building stock in Austria. Advances in Building Energy Research.

Williams, J. (2016). Can low carbon city experiments transform the development regime? Futures 77, 8096. 